\title{
Comment for The Lancet
}

\section{UK role in global health research innovation}

Jenevieve Mannell (UCL), Ibrahim Abubakar (UCL), Andrew Bastawrous (LSHTM), David Osrin (UCL), Preeti Patel (King's College London), Peter Piot (LSHTM), Martin Prince (Kings), Jim Smith (Wellcome Trust), Robert J Wilkinson (Francis Crick Institute), and Richard Horton ${ }^{1}$

Innovation is essential to address the complex problems in global health today-widening inequity, changing patterns of disease burden, the impacts of conflict, migration, natural disasters, and climate change. Many approaches to these challenges are well recognised: crossdisciplinary research, evidence-based practice, and a consideration of the behavioural, cultural, social, political, and economic determinants of health. ${ }^{1}$ Solutions, however, require innovative approaches to ensure the full participation of low-income and middle-income countries (LMICs) in shaping the global health agenda. This is not currently the case: global health's major donors set priorities as part of internal processes that respond only partly to the priorities of LMIC citizens and governments. ${ }^{2}$ Efforts by global health actors to challenge paternalism in the North-South aid relationship are increasingly threatened by the rise of populism in high-income countries (HICs), divisive political movements such as Brexit, and rising inequalities within and between countries. ${ }^{3}$ Overcoming these political challenges will require innovation and activism by the global health community.

As one of the largest bilateral funders, with an annual official development assistance (ODA) budget for health in excess of $f 1$ billion, ${ }^{4}$ the UK has a role in facilitating the active participation of LMICs in developing the global health agenda. With this in mind, we examine

\footnotetext{
${ }^{1}$ This Comment was written by participants in an event on 'The UK Contribution to Innovation in Global Health' held at the Francis Crick Institute on December 4th 2017. The event was organised by leading global health institutions in the UK, including University College London, Imperial College London, London School of Hygiene and Tropical Medicine, King's College London, and the Francis Crick Institute with funding from the Wellcome Trust and Medical Research Council.
} 
the example of UK research and development institutions, and identify some innovative approaches.

First, there is a need to increase the involvement of LMIC partners in identifying what works to address complex global health problems. Experiences of HIV/AIDS in Africa during the 1990s, including the failure of large-scale interventions that relied on western understandings of the epidemic while prevalence skyrocketed, have shown the vital importance of understanding local context. ${ }^{5}$ Examples of initiatives that put LMIC practices and experiences at the heart of intervention design include: a series of local action and community participation interventions to improve maternal and newborn survival outcomes in Bangladesh, India, Malawi, and Nepal; ${ }^{6}$ the use of urban women's and children's community resource centres to respond to the needs of India's National Health Mission; ${ }^{7}$ and responses to gender-based violence based on local need and existing programmes. ${ }^{8}$

Second, understanding local context should inform the use of new technologies as benchmarks for innovation. Indiscriminate use of technology can reinforce existing hierarchies by emphasising LMICs as the problem and HICs as the source of solutions. ${ }^{9}$ Equally, technology designed with local needs and resources in mind can increase the impact of effective interventions. One example of this approach is Peek Vision, a social impact organisation that uses smartphone technology and incentive-based financing to increase access to eye care in Botswana, India, and Kenya. ${ }^{10}$ In Kenya, a locally adapted smartphone app was used by teachers to identify school children with visual impairment; 21000 children were screened by 25 teachers and 900 children identified with visual impairment in only 9 days. Technology alone cannot solve complex problems, but locally adapted technologies can greatly amplify existing efforts. 
Third, innovation is required to overcome the misalignment between research funding that originates in HICs and the needs and priorities of LMICs. For example, an assessment of funding by disease shows that although acute respiratory infections account for $25 \%$ of the infectious disease burden in LMICs, they receive only $3 \%$ of direct aid. ${ }^{11}$ Inequality in the funding relationship between HICs and LMICs is compounded by insufficient funding from LMIC governments-a vicious circle in which human resource and skills shortfalls compromise governments' ability to prioritise global health issues and effective actions.

UK funders are trying to address these problems. Examples include: the $£ 1 \cdot 5$ billion Global Challenges Research Fund for the development needs of ODA-recipient countries; the Wellcome Developing Excellence in Leadership, Training and Science Initiative (DELTAS) for research and training programmes led by African scholars; and the $f 735$ million Newton Fund, which includes partner countries in decision making and financial contributions. These innovative models need to be studied. Major funding schemes from resource-rich settings should be designed to encourage and leverage local LMIC co-funding for better ownership and sustainability of research programmes.

UK innovation in global health arises from an awareness that the full participation of LMICs is essential for solving complex global health problems. Examples of how this can be done are emerging from UK research institutions and funding bodies, including shared funding structures, co-production of interventions and evidence, and locally adapted technologies. However, innovative approaches will require a multiplication of such efforts until LMICs that have the highest burden of disease are actually driving the agenda. In the current political climate, this is a radical proposition that requires us all to become global health activists. 
$A B$ is CEO and receives a salary from Peek Vision Ltd, a wholly owned trading subsidiary of The Peek Vision Foundation. JS is an employee of the Wellcome Trust and has a laboratory in the Francis Crick Institute supported by core funding from the Medical Research Council, Cancer Research UK, and Wellcome.

RJW reports grants from Wellcome, Research Councils UK, National Institutes of Health, European Commission, European \& Developing Countries Clinical Trials Partnership, South African Medical Research Council, Foundation for the National Institutes of Health, and National Research Foundation of South Africa. We declare no other competing interests. This Comment was written by participants in an event on The UK Contribution to Innovation in Global Health held at the Francis Crick Institute, London, UK, on Dec 4, 2017. The event was organised by University College London, Imperial College London, London School of Hygiene \& Tropical Medicine, King's College London, and the Francis Crick Institute with funding from the Wellcome Trust and Medical Research Council.

\section{References:}

1 Sommer M, Parker R. Structural approaches in public health. Abingdon: Routledge, 2013: 285.

2 Sridhar D, Batniji R. Misfinancing global health: a case for transparency in disbursements and decision making. Lancet 2008; 372: 1185-91.

3 Labonté R, Stuckler $D$. The rise of neoliberalism: how bad economics imperils health and what to do about it. J Epidemiol Community Health 2016; 70: 312-18. 
4 Department for International Development. Statistics on international development 2016. London: Department for International Development, 2016. https://www.gov.uk/government/uploads/system/uploads/attachment_data/file/57206 3/statistics-on-international-development-2016a.pdf (accessed Nov 6, 2017).

5 Campbell C. Letting them die: why HIV/AIDS prevention programmes fail. Bloomington: Indiana University Press, 2003: 214.

6 Prost A, Colbourn T, Seward N, et al. Women's groups practising participatory learning and action to improve maternal and newborn health in low-resource settings: a systematic review and meta-analysis. Lancet 2013; 381: 1736-46.

7 More NS, Das S, Bapat U, et al. Community resource centres to improve the health of women and children in informal settlements in Mumbai: a cluster-randomised, controlled trial. Lancet Global Health 2017; 5: e335-49.

8 Jewkes R, Flood M, Lang J. From work with men and boys to changes of social norms and reduction of inequities in gender relations: a conceptual shift in prevention of violence against women and girls. Lancet 2015; 385: 1580-89.

9 Frenk J, Gómez-Dantés O, Moon S. From sovereignty to solidarity: a renewed concept of global health for an era of complex interdependence. Lancet 2014; 383: 94-97.

10 The Peek Vision Foundation. Annual Report and Financial Statements Year Ended December 2016. https://www.peekvision.org/wpcontent/uploads/2017/10/PeekFoundation Annual Report YearEnd Dec2016 DIGITAL. pdf (accessed Feb 9, 2018).

11 Shiffman J. Donor funding priorities for communicable disease control in the developing world. Health Policy Plan 2006; 21: 411-20. 